\title{
Phosphorylation of P68 RNA Helicase by P38 MAP kinase contributes to colon cancer cells apoptosis induced by oxaliplatin
}

Heena Dey and Zhi-Ren Liu ${ }^{*}$

\begin{abstract}
Background: We previously demonstrated that p68 phosphorylation at threonine residues correlates with cancer cell apoptosis under the treatments of TNF-a and TRAIL (Yang, L. Mol Cancer Res Vol 3, pp 355-63 2005).

Results: In this report, we characterized the role of p68 phosphorylation in apoptosis induction under the treatment of oxaliplatin in the colon cancer cells. Our data suggest that oxaliplatin treatment activates p38 MAP kinase, which subsequently phosphorylates p68 at T564 and/or T446. The phosphorylation of p68, at least partially, mediates the effects of the drug on apoptosis induction, as mutations at these two sites greatly reduce the cancer cell death.

Conclusion: Our studies reveal an important molecular mechanism that mediates the effects of anti-cancer drug, providing a potential strategy for improving cancer treatment.
\end{abstract}

Keywords: P68 RNA helicase, Oxaliplatin, Phosphorylation, p38 MAP kinase, DEAD-box, Apoptosis

\section{Background}

Oxaliplatin is a new generation of platinum derivatives that is currently used in the front line for the treatment of human colorectal cancer and other cancers [1]. The therapeutic effects of oxaliplatin may result from the DNA damage caused by the compound, which lead to cell cycle arrest and apoptosis [2,3]. The compound can induce DNA damage by the formation of cross-links between the two strands of DNA, leading to blockage of DNA replication and transcription [3-5]. The compound activates multiple signaling pathways in mediating apoptosis induction [6,7]. It is known that treatment of cancer cells with oxaliplatin results in the activation of p38 and/or JNK kinases, which subsequently target a number of downstream effector molecules leading to cell apoptosis. Although the mechanism underlying the tumor apoptosis induced by the drug has been intensively studied, the detailed mechanism, especially the cellular molecules that contribute to the effects of the drug, is not fully understood.

\footnotetext{
*Correspondence: zliu8@gsu.edu

Department of Biology, Georgia State University, Atlanta, GA 30303, USA
}

Atlanta, GA 30303, USA
P38 is a stress-activated MAP kinase that is activated in response to many cellular stress induction signals, including oxidative stress and toxic chemicals $[8,9]$. Sustained activation of p38 MAP kinase is critical in mediating the effects of the stress signals in the induction of cell apoptosis [10,11]. A number of anti-cancer agents act via activation of $\mathrm{p} 38$, such as platinum compounds [12], etoposide [13], and taxol [14]. P38 Map kinase is activated by phosphorylation at Thr180 and Tyr182 residues in its conserved TGY motif $[15,16]$. The p38 MAP kinase targets a number of very important downstream proteins to exert its effects in apoptosis induction. It is reported that phosphorylation of p53 on Ser46 by p38 is essential for apoptosis induction by several anti-cancer drugs and virus $[17,18]$. Treatment of colon cancer cells with oxaliplatin leads to activation of p38 MAP kinase, which subsequently phosphorylates gamma-H2AX and securin. These phosphorylation events contribute to the cell apoptosis induced by the compound $[19,20]$.

The nuclear p68 RNA helicase is a member of the DEAD box family of RNA helicase [21,22]. P68 RNA helicase plays a very important role in cell proliferation and early organ development and maturation [23]. The

() Biomed Central

(c) 2012 Dey and Liu; licensee BioMed Central Ltd. This is an Open Access article distributed under the terms of the Creative Commons Attribution License (http://creativecommons.org/licenses/by/2.0), which permits unrestricted use, distribution, and reproduction in any medium, provided the original work is properly cited. 
expression of the protein was shown to correlate with tumor progression and transformation [24]. We have previously reported that p68 RNA helicase is phosphorylated at multiple amino acid residues, including serine/ threonine and tyrosine [25]. P68 was phosphorylated at tyrosine residue(s) in a number of different cancer cell lines but not in the corresponding normal cells/tissues. In response to growth factor PDGF-BB stimulation, p68 is phosphorylated at Y593 by c-Abl in HT-29 cells. Phosphorylation of p68 at Y593 promotes EMT via promoting $\beta$-catenin nuclear translocation [26]. P68 acquires a double tyrosine phosphorylation at Y593/Y595 in T98G glioblastoma cells. The double phosphorylation mediates resistance to TRAIL-induced apoptosis. Interestingly, when the cancer cells become apoptotic resistant, double tyrosine phosphorylations of p68 increases while threonine phosphorylation of p68 decreases indicating that p68 threonine phosphorylation may play an important role in mediating the effects of anti-cancer drug in the induction of apoptosis [25]. We report here that, upon the anti-cancer drug oxaliplatin treatment, p68 RNA helicase becomes threonine phosphorylated in colon cancer HCT116 cells. Oxaliplatin treatment activates p38 MAP kinase in the cells, which subsequently phosphorylates p68 at T564 and/or T446. Our results demonstrate that the phosphorylation of p68 at T564 and/or T446 is critically important for the apoptosis induction by the drug. Our studies reveal a very important molecular factor that mediates the effects of anti-cancer drug in apoptosis induction and may suggest a potential therapeutic strategy for cancer treatment.

\section{Results}

Oxaliplatin treatment of colon cancer cells induced p68 threonine phosphorylation

We previously reported that tyrosine phosphorylation of p68 correlates with tumor progression [25]. In studying the effects of several anti-cancer drugs and p68 phosphorylation status, we noted that significantly higher levels of p68 threonine phosphorylation were observed in the colon cancer cells following the treatment with several anti-cancer drugs [25]. We asked whether the phosphorylation of p68 at threonine plays a role in mediating the anti-cancer drug effects. We used oxaliplatin that is commonly used in the treatment of colon cancer patients. Massive cell death of HCT116 cells was induced upon the treatment with the drug at different dosages (Figure 1A). We then examined the threonine phosphorylation of $\mathrm{p} 68$ by the procedure similar to that described in our previous reports [25,27]. It was clear

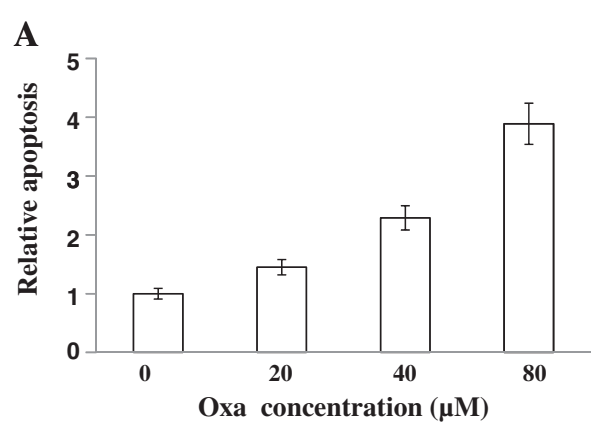

C

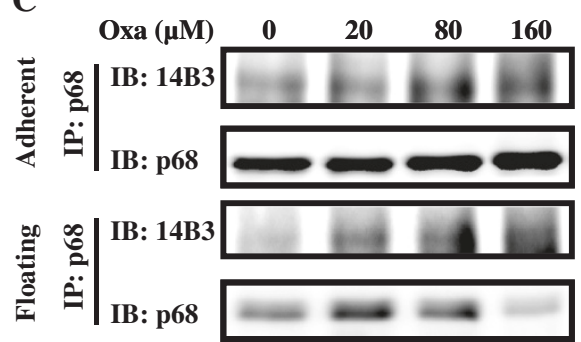

B

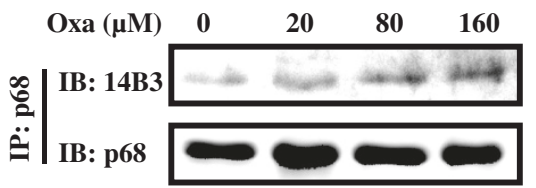

D

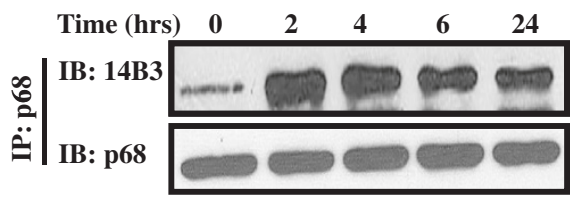

Figure 1 Threonine phosphorylation of p68 in HCT116 cells under oxaliplatin (Oxa) treatment. (A) Apoptosis of HCT116 cells under the treatment of different concentrations of oxaliplatin is measured by a commercial apoptosis kit and presented as Relative apoptosis by defining the apoptosis of the cells without oxaliplatin treatment as 1. Error bars represent standard deviations of four independent experiments. (B), (C), and (D) Threonine phosphorylations of p68 in HCT116 cells that are treated with different concentrations of oxaliplatin (B) and (C) or $20 \mu \mathrm{M}$ of oxaliplatin for different times (D) are analyzed by immunobloting the p68 that is immunoiprecipitated (IP:p68) from cell lysates using antibody against phorsphor-threonine (IB:14B3). Immunoblot of p68 (IB:p68) in immunoprecipitates indicate the amounts of p68 were precipitated down.

In (C), the analyses are carried out with the cells that are already floating (Floating) and the cells that are still adherent (Adherent) under the treatments. 
that oxaliplatin treatment dramatically increased p68 phosphorylation at threonine (Figure 1B). This phosphorylation increase was observed with both the floating cells and the cells that were still attached to the culture plate under the drug treatment (Figure 1C). We subsequently tested the timing of the p68 threonine phosphorylation upon oxaliplatin treatment. It was evident that the p68 threonine phosphorylation reached a peak around $4-6$ hours post drug treatment at the most commonly used drug concentration of $20 \mu \mathrm{M}$. The phosphorylation decreased thereafter (Figure 1D).

\section{P68 is phosphorylated by p38 MAP kinase at T564 and T446 upon the drug treatment}

We next sought to investigate the protein kinase that phosphorylates p68 in response to the anti-cancer drug treatment. It is well known that p38 MAP kinase is strongly activated in colon cancer cells upon the treatment by oxaliplatin. Activation of p38 MAP kinase is critical for the induction of apoptosis of the cancer cells $[11,28]$. To investigate the relation of p68 threonine phosphorylation and p38 MAP kinase activation, we simultaneously probed p68 phosphorylation and phosphorylation of p38 MAP kinase at the TGY motif using a commercially available antibody against the phosphorylated/activated p38 in HCT116 cells. It was clear that p38 MAP kinase was activated upon the oxaliplatin treatment. Interestingly, the timing of p38 MAP kinase activation/phosphorylation correlated very well with the p68 phosphorylation at threonine upon the oxaliplatin treatment (Figure 2A), indicating a possibility that p68 is a target of p38 MAP kinase during the induction of cell apoptosis by the anticancer drug. To test whether p68 is indeed the target of p38 MAP kinase, we examined the interaction of p68 and p38 by co-immunoprecipitation. HCT116 cells expressing endogenous p68 and p38 were treated by oxaliplatin. P68 was immunoprecipitated from the cell extracts prepared from the treated cells using anti-p68 antibody. It was
A

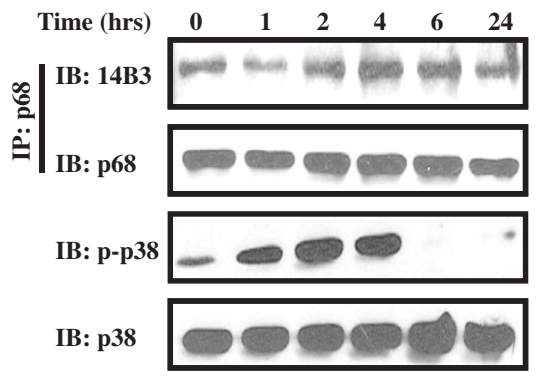

$\mathbf{C}$

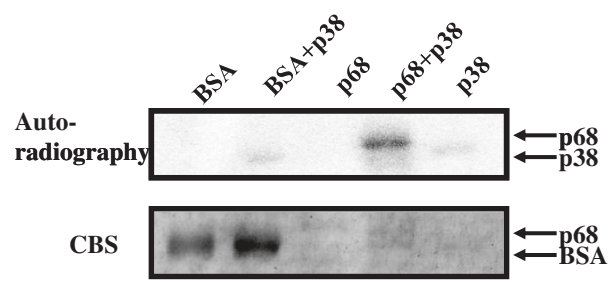

B

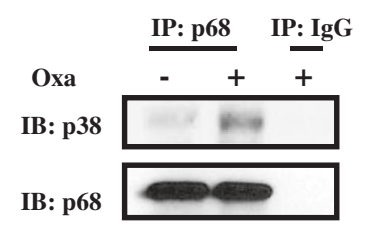

D

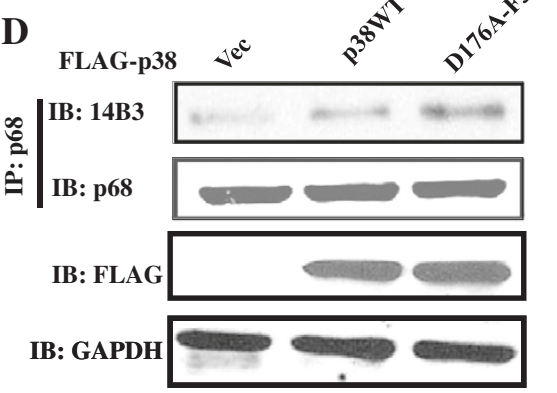

Figure 2 MAPKPhosphorylation of p68 by p38 MAPK. (A) Threonine phosphorylations of p68 in HCT116 cells that are treated with $20 \mu \mathrm{M}$ of oxaliplatin for different times are analyzed by immunobloting the p68 that are immunoiprecipitated (IP:p68) from cell lysates using antibody against phorsphor-threonine (IB:14B3). Phosphorylation of p38 MAPK under the same treatment is analyzed by immunoblot of cell lysates using antibody against the phosphorylated p38. Immunoblot of p68 (IB:p68) in the immunoprecipitates indicate the amounts of p68 that are precipitated. Immunoblot of p38 in the cell lysate (IB:p38) indicate the cellular levels of p38, as a loading control. (B) Co-immunoprecipitation of p38 and p68 in the cell extracts of HCT116 cells with/without oxaliplatin treatment (Oxa, $+/-20 \mu \mathrm{M})$ was analyzed by immunoblot of p68 immunoprecipitates (IP:p68) using antibody against p38 (IB:p38). Immunoblot of p68 (IB:p68) in the immunoprecipitates indicate the amounts of p68 that are precipitated. IP:IgG is the immunoprecipitation using rabbit lgG, serving as a negative control IP. (C) Phosphorylation of recombinant His-p68 or BSA, as a control, by recombinant p38 in the presence of [ $\left.\gamma^{-}{ }^{32} \mathrm{P}\right]-\mathrm{ATP}$ is revealed by autoradiography. The amounts of proteins used in the phosphorylation reactions are shown by coomasie blue stains (CBS). (D) Phosphorylation of p68 by exogenous expression of Flag-tagged p38 MAPK, wild type and constitutively active mutant D176A-F327L, in HCT116 cells are analyzed by immunoblotting the p68 that are immunoiprecipitated (IP:p68) from cell lysates using antibody against phorsphor-threonine (IB:14B3). Immunoblot of p68 (IB:p68) in immunoprecipitates indicate the amounts of p68 that are precipitated. Immunoblot of Flag-tag (IB:FLAG) indicate the exogenous p38 levels. Immunoblot of GAPDH (IB:GAPDH) is a loading control. 
evident that p38 coimmunoprecipitated with p68 (Figure 2B). We then further verified the phosphorylation of p68 by p38 MAP kinase by carrying out an in vitro phosphorylation using recombinant p68 and p38 MAP kinase. It was clear that the recombinant p68 was phosphorylated by the recombinant p38. As a control, BSA was not phosphorylated by the recombinant MAP kinase (Figure 2C). To further confirm that p38 indeed phosphorylated p68 at threonine residue, we used a constitutively activated p38 mutant D176A-F327L. D176A-F327L was expressed in HCT cells. Phosphorylation of p68 at threonine residue(s) in cells was examined by the immunoprecipitation and immunoblot procedures. Apparently, phosphorylation of p68 at threonine was dramatically increased upon the p38 mutant expression (Figure 2D). We concluded from our studies that p68 is phosphorylated by 38 MAP kinase upon the apoptosis induction by anti-cancer drug treatment.

We next determined the potential p68 phosphorylation sites by p38 MAP kinase. We carried out a phosphorylation site search using a web-based program. The consensus phosphorylation site search indicated several potential S/T phosphorylation sites (Figure 3A). Based on the phosphorylation site prediction, we made several mutants that carried mutation at the predicted phosphorylation sites (Figure 3A). In vitro phosphorylation reaction with the generated mutants using the recombinant p38 indicated that there was a significant decrease in p68 phosphorylation with the mutant T564A, while there was almost no change with other mutants (Figure 3B, Upper panel), indicating that T564 is a potential site. To verify whether the T564 is the phosphorylation site, the T564A mutant or other mutants were expressed in HCT116 cells. After the cells were treated with oxaliplatin, phosphorylation of the p68 mutant at threonine was examined. Surprisingly, there was no change in p68 threonine phosphorylation with wild type and any mutant (Figure 3C Upper panel). One possible explanation is that p68 may have additional phosphorylation sites by p38 MAP kinase. It is well established that p38 MAP kinase often phosphorylates multiple sites in its targets $[29,30]$. To test this possibility, we created two

\begin{tabular}{|c|c|c|c|c|}
\hline \multicolumn{5}{|l|}{$\mathbf{A}$} \\
\hline MEF2C & Q S L A & $T$ & $\mathbf{P}$ & V V S \\
\hline MAPKAPK2 & K V P Q & $T$ & $\mathbf{P}$ & L H T \\
\hline ATF-2 & D Q T $P$ & $\mathrm{~T}$ & $\mathbf{P}$ & $\int T R F$ \\
\hline P68-T610 & Y P M $\mathbf{P}$ & $T$ & G & Y S Q \\
\hline P68-T564 & T G N P & $T$ & G & T Y Q \\
\hline P68-T446 & Y T F F & $T$ & $P$ & N N I \\
\hline Р68-T224 & I C I A & $\mathbf{T}$ & $\mathbf{P}$ & G R L \\
\hline
\end{tabular}

C

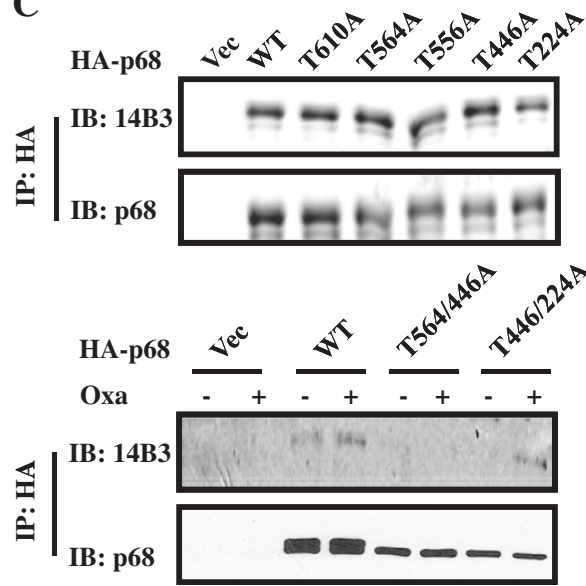

B

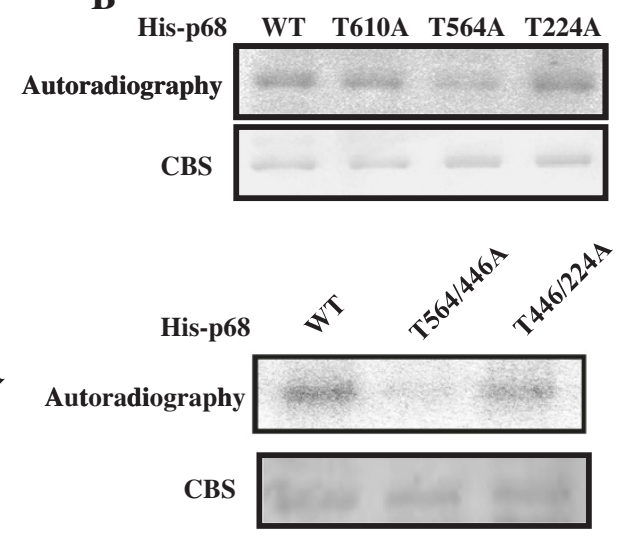

Figure 3 Phosphorylation site(s) of p68 by p38 MAPK. (A) Prediction of potential p38 MAPK phosphorylation site(s) in the p68 reading frame and compared to the consensus p38 MAPK phosphorylation sites of several authentic p38 MAPK substrates by a web-based phosphorylation site prediction program NetPhos 2.0, (B) Phosphorylation of recombinant His-p68 and mutants with single site mutation (Upper) and double site mutations (Lower) by recombinant p38 in the presence of $\left[\mathrm{Y}^{-32} \mathrm{P}\right]$-ATP is revealed by autoradiography. The amounts of proteins used in the phosphorylation reactions are shown by coomasie blue stains (CBS). (C) Phosphorylation of exogenously expressed HA-p68s, wild type (WT) and mutants (Single site mutation, Upper, and Double site mutations, Lower), in HCT116 cells with/without oxaliplatin treatment (Oxa, $+/-)$ are analyzed by immunoblotting the p68 that is immunoiprecipitated (IP:p68) from cell lysates using antibody against phorsphor-theronine (IB:14B3). Immunoblot of p68 (IB:p68) in immunoprecipitates indicate the amounts of p68 that are precipitated. 
p68 double mutants, T564/446A and T446/224A. The in vitro phosphorylation was carried out with these two mutants. It was clear that phosphorylation of T564/ 446A by p38 MAP kinase was almost abolished, while the phosphorylation of T446/224A had very minor reduction (Figure 3B Lower panel). The in vitro phosphorylation results suggested that it is likely that the T564 and T446 of p68 are the phosphorylation sites by p38. To verify whether indeed the T564 and T446 are the phosphorylation sites, HA-tagged p68 wt, T564/446A, and T446/T224A were expressed in HCT116 cells. The cells were treated by oxaliplatin. Phosphorylations of the HA-tagged p68 wt and the mutants were examined. Clearly, phosphorylation of T446/T224A experienced a minor decrease, while phosphorylation of T564/446A was almost abolished (Figure $3 \mathrm{C}$ Lower panel). The results strongly argued that p38 phosphorylated p68 at T564 and T446 upon the apoptosis induction by anticancer drug.

Phosphorylation of p68 at threonine mediates the effects of oxaliplatin in the induction of apoptosis

We next investigated whether the p68 threonine phosphorylation by p38 plays a role in mediating the effects of the anti-cancer drug. To this end, the endogenous p68 was knocked down in HCT116 cells. HA-tagged at p68 or T564/446A was expressed in the p68 knockdown cells (Figure 4A). The cells were then subsequently treated by oxaliplatin at a concentration of $10 \mu \mathrm{M}$. Cell apoptosis was measured using a commercially available apoptosis assay kit (caspase- 3 assay). There were no significant changes in cell apoptosis without oxaliplatin treatment. However, oxaliplatin induced apoptosis was dramatically reduced with the T564/446A expressing cells. This effect was not observed with the wt p68 expressing cells (Figure 4B). Similar results were observed with MTT assays (Figure 4C). Thus, we conclude that phosphorylation of p68 at T564/446 by p38, at least partially, mediates the effects of oxaliplatin on apoptosis induction.

\section{Discussion}

In this report, we describe that p68 RNA helicase is phosphorylated at T564 and/or T446 in colon cancer HCT116 cells upon the anti-cancer drug oxaliplatin treatment. The protein is phosphorylated by p38 MAP kinase upon the drug treatment. The phosphorylation(s) of p68 contributes to the effects of apoptosis induction by the drug. Our results echo our previous report that the loss of p68 threonine phosphorylation correlates with cancer cell TRAIL
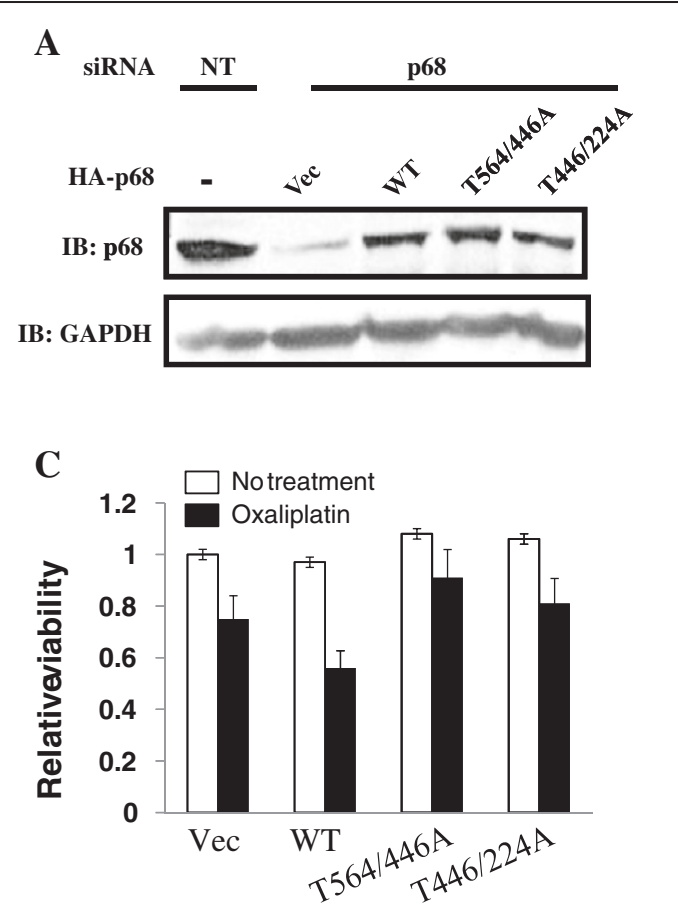

B

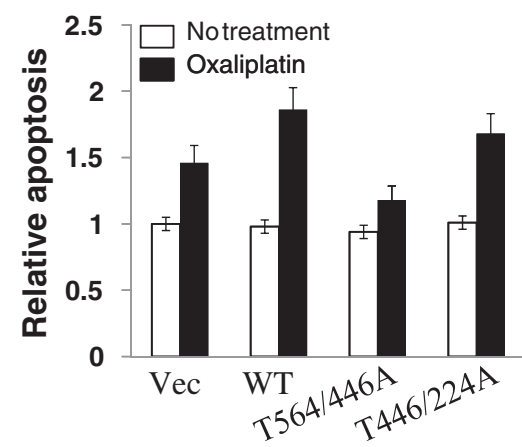

Figure 4 Effects of p68 phosphorylation on cell apoptosis. (A) HCT116 cells are treated by non-targeting siRNA (NT) or siRNA target p68 (p68). HA-p68, wild type and indicated mutants, are expressed in the p68 knockdown cells. Immunoblot of p68 (IB:p68) indicates the cellular levels of p68 (both endogenous and exogenous). Immunoblot of GAPDH (IB:GAPDH) is a loading control. (B) and (C). Cell apoptosis (B) and viability $(\mathbf{C})$ of the cells in $(\mathbf{A})$ that are treated or untreated with oxaliplatin are measured by a commercial apoptosis kit (B) or MTT assay $(\mathbf{C})$. The cell apoptosis and viability are presented as relative apoptosis and relative viability by defining the apoptosis and viability of the vector expressing cells without oxaliplatin treatment as 1. Error bars represent standard deviations of four independent experiments. 
resistance [27]. Thus, phosphorylation of p68 at T564 and T446 may represent a common molecular mechanism that acts in multiple pathways of apoptosis induction.

It is well established that activation of p38 MAP kinase is a common pathway for multiple apoptosis inducers, including a number of anti-cancer drugs with different molecular mechanisms [7,13,31], oxidative stresses [8], cells damaged by UV light [32]. However, the downstream targets that mediate the effects are not very clear. In fact, only a few substrates of p38 MAP kinase have been identified that have a role in cell apoptosis induction, including p53 [17] and HSP27 [33,34], and the mechanism by which phosphorylation of these substrates mediates the effects of apoptosis induction is not fully understood.

How the phosphorylation of p68 at T564 and T446 mediates cell apoptosis is an open question. One plausible explanation is that the phosphorylated p68 may change p68 interacting partners in the cells, which allows p68 to target a particular apoptosis mediating protein or complex. The consequence for the p68 targeting is activation of apoptotic function of the targeted protein or complex. It is known that a number of DEAD box RNA helicases associate with apoptosis induction protein or complex. For example DDX42 modulates the apoptotic function of ASPP2 by direct interaction with it [35]. Interaction between GABA receptor associated protein (GABARAP) and DDX47 is required for induction of neuronal cell apoptosis [36]. However, it is not known how this DEAD box RNA helicase regulates the apoptotic process. In this regard, it will be interesting to probe whether phosphorylation of p68 at T564 and/or T446 mediates the association of the protein with a particular apoptosis inducing complex to activate the complex. Among these potential interacting partners, p53 and p68 interaction is of particular intriguing, p68 was shown to interact with p53 to mediate the effects of p53 downstream targets. It is also well established that oxaliplatin induces cell apoptosis via activation of p38, which subsequently phosphorylates p53 in human colorectal cancer cells $[37,38]$. Thus, role of existence of p53 function in apoptosis induction related to the p68 Thr phosphorylation is an interesting potential.

\section{Methods}

\section{Cell culture and antibodies}

Human HCT116 cells were obtained from ATCC (Manassas, VA, USA) and were cultured according to vendor's instruction. Antibodies against p68 were raised against bacterially expressed His-tagged C-terminal domain (a.a.437-614) of human p68 (Invitrogen, Carlsbad, CA, USA, Auburn University Hybridoma Facility). Antibodies against $\beta$-actin, phosphor-theronine (14B3), p38 and phosphor-p38, HA-tag, Flag-tag, and GAPDH were purchased from Santa Cruz, BD Bioscience, and Roche Applied Science respectively.

\section{Drug treatment, DNA constructs, transfections, and siRNA} interference

Oxaliplatin was purchased from Sigma and dissolved in water to prepare a stock solution of $2.5 \mathrm{mM}$. The stock solution was stored at $-20^{\circ} \mathrm{C}$ and diluted with medium to prepare working concentrations. The cDNA of p68 ORF was subcloned into pHM6 vector (Roche) at HindIII site to get HA-tagged p68 expression vector. The various p68 single and double threonine mutants (threonine replaced by alanine) were generated by QuickChange site-directed mutagenesis kit (Stratagene) and the mutations were confirmed by DNA sequencing. P38 $\alpha$ cDNA (Origene) was subcloned into p3XFLAGmyc-CMV ${ }^{\mathrm{Tm}}-24$ Expression Vector (Sigma). A number of mutations to get the constitutively active form of p38 were done using the reference [39]. All DNA transfections were performed using fugene $\mathrm{HD}$ (Roche) and lipofectamine 2000 (Invitrogen) while siRNA transfections were done with lipofectamine RNAimax (Invitrogen). The duplex siRNA against p68 was purchased from Dharmacon and the sequence was as follows: siRNA oligonucleotides against p68 (sense: GCAA GUAGCUGCUGAAUAUUU; antisense: AUAUUCAG CAGCUACUUGCUU). Cells were transfected with the indicated plasmids 24 hrs after p68 siRNA knockdown and further treated with the drug for $24 \mathrm{hrs}$. The cells were then harvested for nuclear extract preparation using a kit from Active motif.

\section{Protein expression and purification}

The procedure used to express and purify p68 is similar to the procedure reported previously. P68 ORF was cloned and various mutants were cloned into expression vector pET-30a+ using the restriction sites BamHI/ HindIII and transformed into E.coli BL21-CodonPlus bacteria (Stratagene) were used to express protein. The bacteria were subcultured in fresh st. LB broth till OD reached between 0.5 to 0.8 units at $600 \mathrm{~nm}$ and then subsequently induced with $0.5 \mathrm{mM}$ IPTG for $18 \mathrm{hrs}$ at $16^{\circ} \mathrm{C}$. The cells were harvested, washed with $1 \mathrm{X}$ PBS buffer, pelleted and stored at $-80^{\circ} \mathrm{C}$. The cells were then disrupted by one freeze-thaw cycle at $-80^{\circ} \mathrm{C}$, resuspended in lysis buffer (50mM Tris- $\mathrm{HCl} \mathrm{pH} 8.0,300 \mathrm{mM} \mathrm{NaCl}$, $1 \mathrm{mM}$ DTT, 10mM PMSF, $10 \%$ glycerol) and subjected to lysozyme $(0.5 \mathrm{mg} / \mathrm{ml})$ digestion. DTT and PMSF were also added at $1 \mathrm{mM}$ final concentration. The cells were further subjected to ultrasonication and pelleted. After centrifugation, the expressed protein was found to be precipitated in the bacterial inclusion bodies (IB). The IB were dissolved in denaturing buffer containing $8 \mathrm{M}$ urea, 
$50 \mathrm{mM}$ Tris- $\mathrm{HCl} \mathrm{pH} 8.0,250 \mathrm{mM} \mathrm{NaCl}$ and $0.2 \%$ Triton100. The lysate was passed through Ni-NTA column for purification of recombinant protein by affinity separation and the column was washed with the denaturing wash buffer $(8 \mathrm{M}$ urea, $50 \mathrm{mM}$ Tris- $\mathrm{HCl} \mathrm{pH} 8.0,250 \mathrm{mM} \mathrm{NaCl}$, $0.2 \%$ Triton- 100 and $20 \mathrm{mM}$ imidazole $\mathrm{pH}$ 8.0). The protein was finally eluted with elution buffer containing $250 \mathrm{mM}$ Imidazole, $8 \mathrm{M}$ urea, $50 \mathrm{mM}$ Tris- $\mathrm{HCl} \mathrm{pH} 8.0$, $250 \mathrm{mM} \mathrm{NaCl}, 0.2 \%$ Triton-100, $0.5 \mathrm{mM}$ DTT and $10 \%$ glycerol. The eluted protein solution was refolded using stepwise dialysis procedure $(8 \mathrm{M} \rightarrow 6 \mathrm{M} \rightarrow 4 \mathrm{M} \rightarrow 2 \mathrm{M} \rightarrow 0 \mathrm{M})$ to remove urea using refolding buffer $(200 \mathrm{mM}$ arginine, $50 \mathrm{mM}$ Tris- $\mathrm{HCl} \mathrm{pH} \mathrm{8.0,250mM} \mathrm{NaCl}, 0.2 \%$ Triton- 100 , $0.5 \mathrm{mM} \mathrm{DTT}$ and $10 \%$ glycerol) and preserved in further 15 to $20 \%$ glycerol.

\section{In vitro kinase assay}

In this assay, about $1 \mu \mathrm{g}$ of purified proteins were added to the reaction mixture consisting of 200-250ng of p38 $\alpha /$ SAPK2a enzyme (Upstate cell signaling), $10 \mu \mathrm{Ci} / \mu \mathrm{l}$ of [ $\gamma$-32P]ATP, Magnesium/ATP cocktail $(75 \mathrm{mM} \mathrm{MgCl} 2$ and $500 \mu \mathrm{M}$ ATP in $20 \mathrm{mM}$ MOPS, $\mathrm{pH} 7.2,25 \mathrm{mM} \beta$ glycerol phosphate, $5 \mathrm{mM}$ EGTA, $1 \mathrm{mM}$ sodium orthovanadate and $1 \mathrm{mM}$ dithiothreitol) and $5 \mathrm{X}$ reaction buffer (125 mM Tris-HCl, pH 7.5 and 0.1mM EGTA) in a total volume of $25 \mu \mathrm{l}$. After incubation at $30^{\circ} \mathrm{C}$ for $30 \mathrm{mins}$, $5 \mathrm{X}$ loading buffer (Fermentas) was added to stop the reaction. The samples were then analyzed by running two 10\% SDS-PAGE gels. One of the gels was stained with Coomassie blue staining solution and destained and the other gel was dried and subjected to autoradiography.

\section{Cell viability and apoptosis assay}

Cell viability of HCT116 cells was measured using (3[4,5-dimethylthiazol-2-yl]-2,5-diphenyl tetrazolium bromide) or MTT (Sigma). 4000 cells were seeded per well of 96 well plate 24 hrs before knockdown and transfection of p68 and the mutants. Subsequently, $24 \mathrm{hrs}$ after transfection, the cells were treated with oxaliplatin for $24 \mathrm{hrs}$. Next day, reconstituted MTT reagent was added in an amount equal to $10 \%$ of the culture medium volume and the cells were incubated at $37^{\circ} \mathrm{C}$ for a further $4 \mathrm{hrs}$. The formazan crystals were dissolved by adding MTT Solubilization solution. Cell viability was measured spectrophotometrically by reading the absorbance at a wavelength of $570 \mathrm{~nm}$.

Cells plated on 6 well plates were treated with oxaliplatin after p68 knockdown and transfections and the activity of caspase-3 was measured using caspase-3/ CPP32 colorimetric assay kit (Biovision Research products). Briefly, after apoptosis induction, the cells were resuspended in Cell Lysis Buffer for 10 mins and centrifuged. $50 \mu \mathrm{g}$ of proteins were diluted in Cell Lysis Buffer to which $2 \mathrm{X}$ Reaction buffer and $4 \mathrm{mM}$ DEVD-pNA substrate were added and incubated at $37^{\circ} \mathrm{C}$. The samples were read at $405 \mathrm{~nm}$ using a microtiter plate reader. The cells were treated with oxaliplatin at previously indicated concentration and time and apoptosis was measured using FITC Annexin V Apoptosis Detection Kit (BDbiosciences). The brief description of the procedure is as follows: The cells were washed twice with cold $1 \mathrm{X}$ PBS after treatment and resuspended in 1X Annexin Binding Buffer at a final concentration of $1 \times 10^{6} \mathrm{cells} / \mathrm{ml}$. To $1 \times 10^{5}$ cells $(100 \mu \mathrm{l})$ in a $5 \mathrm{ml}$ FACS tube, $5 \mu$ l of FITC Annexin V and $5 \mu \mathrm{l}$ of PI were added, gently vortexed and incubated at room temperature for 15 mins in the dark. Finally, 400 $\mu \mathrm{l}$ of 1X Annexin Binding Buffer was added and the samples were analyzed by flow cytometry within $1 \mathrm{hr}$.

\section{Competing interests}

The authors declare that they have no competing interests.

\section{Authors' contribution}

Heena Dey carried out all the experiments and analysis of experimental data. She also contributed partially to experimental designed and to the preparation of the manuscript. ZR Liu is responsible for experimental design and the preparation of the manuscript. All authors read and approved the final manuscript.

\section{Acknowledgments}

We thank Roger Bridgeman for antibody p68-rgg production. This manuscript is greatly improved by critical comments from Jenny J. Yang. This work is supported in part by research grants from National Institute of Health (GM063874) and Georgia Cancer Coalition to ZR Liu.

Received: 28 June 2012 Accepted: 15 October 2012

Published: 31 October 2012

\section{References}

1. Raymond E, Faivre S, Woynarowski JM, Chaney SG: Oxaliplatin: mechanism of action and antineoplastic activity. Semin Oncol 1998, 25(2 Suppl 5):4-12.

2. Rakitina TV, Vasilevskaya IA, O'Dwyer PJ: Inhibition of G1/S transition potentiates oxaliplatin-induced cell death in colon cancer cell lines. Biochem Pharmacol 2007, 73(11):1715-1726.

3. Faivre S, Le Chevalier T, Monnerat C, Lokiec F, Novello S, Taieb J, Pautier P, Lhomme C, Ruffie P, Kayitalire L, et al: Phase I-II and pharmacokinetic study of gemcitabine combined with oxaliplatin in patients with advanced non-small-cell lung cancer and ovarian carcinoma. Annals of oncology: official journal of the European Society for Medical Oncology / ESMO 2002, 13(9):1479-1489.

4. Ang WH, Myint M, Lippard SJ: Transcription inhibition by platinum-DNA cross-links in live mammalian cells. J Am Chem Soc 2010, 132(21):7429-7435.

5. Fischel JL, Formento P, Ciccolini J, Rostagno P, Etienne MC, Catalin J, Milano $\mathrm{G}$ : Impact of the oxaliplatin-5 fluorouracil-folinic acid combination on respective intracellular determinants of drug activity. Br J Cancer 2002, 86(7):1162-1168

6. Chiu SJ, Lee YJ, Hsu TS, Chen WS: Oxaliplatin-induced gamma-H2AX activation via both p53-dependent and -independent pathways but is not associated with cell cycle arrest in human colorectal cancer cells. Chem Biol Interact 2009, 182(2-3):173-182.

7. Wang $X$, Li M, Wang J, Yeung CM, Zhang H, Kung HF, Jiang B, Lin MC: The $\mathrm{BH} 3-$ only protein, PUMA, is involved in oxaliplatin-induced apoptosis in colon cancer cells. Biochem Pharmacol 2006, 71(11):1540-1550.

8. Lu Q, Rau TF, Harris V, Johnson M, Poulsen DJ, Black SM: Increased p38 mitogen-activated protein kinase signaling is involved in the oxidative stress associated with oxygen and glucose deprivation in neonatal hippocampal slice cultures. Eur J Neurosci 2011, 34(7):1093-1101.

9. Gould GW, Cuenda A, Thomson FJ, Cohen P: The activation of distinct mitogen-activated protein kinase cascades is required for the stimulation of 2-deoxyglucose uptake by interleukin-1 and insulin-like growth factor-1 in KB cells. Biochem J 1995, 311(Pt 3):735-738. 
10. Zarubin T, Han J: Activation and signaling of the p38 MAP kinase pathway. Cell Res 2005, 15(1):11-18.

11. Xia Z, Dickens M, Raingeaud J, Davis RJ, Greenberg ME: Opposing effects of ERK and JNK-p38 MAP kinases on apoptosis. Science 1995, 270(5240):1326-1331.

12. Wang D, Lippard SJ: Cellular processing of platinum anticancer drugs. Nat Rev Drug Discov 2005, 4(4):307-320.

13. Wood $\amalg$, Nail LM, Perrin NA, Elsea CR, Fischer A, Druker BJ: The cancer chemotherapy drug etoposide (VP-16) induces proinflammatory cytokine production and sickness behavior-like symptoms in a mouse model of cancer chemotherapy-related symptoms. Biol Res Nurs 2006, 8(2):157-169.

14. Shtil AA, Mandlekar S, Yu R, Walter RJ, Hagen K, Tan TH, Roninson IB, Kong AN: Differential regulation of mitogen-activated protein kinases by microtubule-binding agents in human breast cancer cells. Oncogene 1999, 18(2):377-384.

15. New $L$, Han J: The p38 MAP kinase pathway and its biological function. Trends Cardiovasc Med 1998, 8(5):220-228.

16. Gong $X$, Ming $X$, Deng $P$, Jiang $Y$ : Mechanisms regulating the nuclear translocation of p38 MAP kinase. J Cell Biochem 2010, 110(6):1420-1429.

17. Perfettini JL, Castedo M, Nardacci R, Ciccosanti F, Boya P, Roumier T, Larochette N, Piacentini M, Kroemer G: Essential role of p53 phosphorylation by p38 MAPK in apoptosis induction by the HIV-1 envelope. J Exp Med 2005, 201(2):279-289.

18. Perfettini JL, Castedo M, Roumier T, Andreau K, Nardacci R, Piacentini M, Kroemer G: Mechanisms of apoptosis induction by the HIV-1 envelope. Cell Death Differ 2005, 12(Suppl 1):916-923.

19. Chiu SJ, Chao JI, Lee YJ, Hsu TS: Regulation of gamma-H2AX and securin contribute to apoptosis by oxaliplatin via a p38 mitogen-activated protein kinase-dependent pathway in human colorectal cancer cells. Toxicol Lett 2008, 179(2):63-70.

20. Liu WM, Liu RJ, Li ZL: [GammaH2AX-mediated repair of DNA damaged sperm in the zygote]. Zhonghua nan ke xue = National journal of andrology 2010, 16(4):349-353.

21. Crawford L, Leppard K, Lane D, Harlow E: Cellular proteins reactive with monoclonal antibodies directed against simian virus $40 \mathrm{~T}$-antigen. $J$ Virol 1982, 42(2):612-620

22. Lane DP, Hoeffler WK: SV40 large $T$ shares an antigenic determinant with a cellular protein of molecular weight 68,000 . Nature 1980, 288(5787):167-170

23. Stevenson RJ, Hamilton SJ, MacCallum DE, Hall PA, Fuller-Pace FV: Expression of the 'dead box' RNA helicase p68 is developmentally and growth regulated and correlates with organ differentiation/maturation in the fetus. J Pathol 1998, 184(4):351-359.

24. Causevic M, Hislop RG, Kernohan NM, Carey FA, Kay RA, Steele RJ, FullerPace FV: Overexpression and poly-ubiquitylation of the DEAD-box RNA helicase p68 in colorectal tumours. Oncogene 2001, 20(53):7734-7743.

25. Yang L, Lin C, Liu ZR: Phosphorylations of DEAD box p68 RNA helicase are associated with cancer development and cell proliferation. $\mathrm{Mol}$ Cancer Res 2005, 3(6):355-363.

26. Yang L, Lin C, Liu ZR: P68 RNA Helicase Mediates PDGF-Induced Epithelial Mesenchymal Transition by Displacing Axin from beta-Catenin. Cell 2006, 127(1):139-155.

27. Yang L, Lin C, Sun SY, Zhao S, Liu ZR: A double tyrosine phosphorylation of P68 RNA helicase confers resistance to TRAIL-induced apoptosis. Oncogene 2007, 26(41):6082-6092.

28. Holmes WF, Soprano DR, Soprano KJ: Early events in the induction of apoptosis in ovarian carcinoma cells by CD437: activation of the p38 MAP kinase signal pathway. Oncogene 2003, 22(41):6377-6386.

29. Yang TT, Xiong Q, Enslen H, Davis RJ, Chow CW: Phosphorylation of NFATc4 by p38 mitogen-activated protein kinases. Mol Cell Biol 2002, 22(11):3892-3904.

30. De Chiara G, Marcocci ME, Torcia M, Lucibello M, Rosini P, Bonini P, Higashimoto Y, Damonte G, Armirotti A, Amodei S, et al: Bcl-2 Phosphorylation by p38 MAPK: identification of target sites and biologic consequences. J Biol Chem 2006, 281(30):21353-21361.

31. Wang D, Li H, Yuan H, Zheng M, Bai C, Chen L, Pei X: Humanin delays apoptosis in K562 cells by downregulation of P38 MAP kinase. Apoptosis 2005, 10(5):963-971.

32. Tanos T, Marinissen MJ, Leskow FC, Hochbaum D, Martinetto H, Gutkind JS, Coso OA: Phosphorylation of c-Fos by members of the p38 MAPK family. Role in the AP-1 response to UV light. J Biol Chem 2005, 280(19):18842-18852.

33. Deschesnes RG, Huot J, Valerie K, Landry J: Involvement of p38 in apoptosis-associated membrane blebbing and nuclear condensation. Mol Biol Cell 2001, 12(6):1569-1582.

34. Gonzalez-Mejia ME, Voss OH, Murnan EJ, Doseff Al: Apigenin-induced apoptosis of leukemia cells is mediated by a bimodal and differentially regulated residue-specific phosphorylation of heat-shock protein-27. Cell Death \& Dis 2010, 1:e64.

35. Uhlmann-Schiffler $H$, Kiermayer $S$, Stahl $H$ : The DEAD box protein Ddx42p modulates the function of ASPP2, a stimulator of apoptosis. Oncogene 2009, 28(20):2065-2073.

36. Lee $J H$, Rho $S B$, Chun T: GABAA receptor-associated protein (GABARAP) induces apoptosis by interacting with DEAD (Asp-Glu-Ala-Asp/His) box polypeptide 47 (DDX 47). Biotechnol Lett 2005, 27(9):623-628.

37. Nicol SM, Bray SE, Derek Black H, Lorimore SA, Wright EG, Lane DP, Meek DW, Coates PJ, Fuller-Pace FV: The RNA helicase p68 (DDX5) is selectively required for the induction of p53-dependent p21 expression and cellcycle arrest after DNA damage. Oncogene 2012,

38. Bates GJ, Nicol SM, Wilson BJ, Jacobs AM, Bourdon JC, Wardrop J, Gregory DJ, Lane DP, Perkins ND, Fuller-Pace FV: The DEAD box protein p68: a novel transcriptional coactivator of the p53 tumour suppressor. EMBO $J$ 2005, 24(3):543-553.

39. Diskin R, Askari N, Capone R, Engelberg D, Livnah O: Active mutants of the human p38alpha mitogen-activated protein kinase. J Biol Chem 2004, 279(45):47040-47049.

doi:10.1186/1471-2121-13-27

Cite this article as: Dey and Liu: Phosphorylation of P68 RNA Helicase by P38 MAP kinase contributes to colon cancer cells apoptosis induced by oxaliplatin. BMC Cell Biology 2012 13:27.

\section{Submit your next manuscript to BioMed Central and take full advantage of:}

- Convenient online submission

- Thorough peer review

- No space constraints or color figure charges

- Immediate publication on acceptance

- Inclusion in PubMed, CAS, Scopus and Google Scholar

- Research which is freely available for redistribution 